\title{
Reflexões de uma Educadora Sobre o Conceito de Vivência (Erlebnis) e o Filme "Dias de Nietzsche em Turim"
}

\author{
Rosana Cristina Macelloni Alvarenga ${ }^{1}$ \\ ${ }^{1}$ Universidade Estadual Paulista Júlio de Mesquita Filho - UNESP \\ Possui graduação em LICENCIATURA PLENA EM MATEMÁTICA pela UNESP-Bauru (1998). MESTRADO EM EDUCAÇÃO \\ pela UNESP- Marília (2008). DOUTORANDA EM EDUCAÇÃO PARA A CIÊNCIA -UNESP/BAURU. \\ rosanamacelloni@bol.com.br
}

Recebido em 24 de maio de 2015; Aceito em 14 de dezembro de 2016.

\begin{abstract}
Resumo
Este trabalho trata a respeito de reflexões realizadas por uma Educadora sobre o conceito de vivência (Erlebnis) e o filme "Dias de Nietzsche em Turim", com a finalidade de compreender o conceito de vivência e sua importância para a formação das pessoas, por não fazer mais sentido dissociar Filosofia e Educação e por fazer-se necessário outro modo de conceber o humano. Neste sentido, a partir do conceito Erlebnis, a leitura do filme de Julio Bressane traz a relação da natureza física e psicológica de um filósofo com o modo de pensar próprio de Nietzsche, o qual desafiou a humanidade a pensar por si mesma, seguir em frente com total liberdade, propôs ao ser humano o superar-se a si mesmo, transcender-se, e na incorporação de vivências, formar-se. A experiência humana não é agradável de maneira geral e Nietzsche buscou respostas filosóficas ao sofrimento da existência. Pioneiro numa nova forma de pensar, enfraqueceu as crenças morais e religiosas e lembrou de que a vida está aí para construí-la, então que a construamos com as nossas vivências. Dessa interpretação, surgiram novas perguntas e algumas respostas em busca de uma melhor, mais frutífera e mais humana de Educação.
\end{abstract}

Palavras-chave: Educação. Vivência, Nietzsche, Filosofia.

\begin{abstract}
This work is about reflections carried out by an educator on the concept of experience (Erlebnis) and the film "Days of Nietzsche in Turin", in order to understand the concept of experience and your importance to people, not make more sense to dissociate Philosophy and Education and make it necessary another way of looking at human. In this sense, from Erlebnis concept, reading of Julio Bressane film brings the relationship of physical and psychological nature of a philosopher with the thinking of Nietzsche himself, who challenged humanity to think for yourself, move on with total freedom, proposed to overcome the human being himself, transcend ourselves and the incorporation of experiences, to form. Human experience is not pleasant in general and Nietzsche sought philosophical responses to the suffering of existence, pioneering a new way of thinking, it weakened our moral and religious beliefs and reminded us that life is there to build it, so that we build with our experiences ... this interpretation arose new questions and some answers in search of a better, more fruitful and more humane education.
\end{abstract}

Keywords: Experience, Nietzsche, Philosophy 
"A vida é aquilo que acontece enquanto você está planejando o futuro" John Lennon

\section{INTRODUÇÃO}

As questões fundamentais deste trabalho são: qual a gênese e significados do conceito de vivência (Erlebnis)? Qual é o papel da vivência na formação do ser humano? Que vivências de Nietzsche, o filme nos traz? O que estas vivências contribuem para a Educação? Como se deu esta vivência do filme para a autora do trabalho?

Aqui, neste trabalho de análise de conceito e de um filme, acredita-se que empreender essa análise significa tentar entender e explicar como Filosofia e Educação andam juntas. Com ele busca-se o estudo de um conceito fundamental para a formação da pessoa e dessa (re)flexão surgem novas ideias sempre para que o ensino e o aprendizado impulsionem o desenvolvimento do indivíduo, como um ser humano ético, criativo e agente de transformações sociais, uma pessoa íntegra, com pleno desenvolvimento de suas capacidades, para conseguir atuar de forma justa, democrática e consciente, numa sociedade cada vez mais caótica na qual vivemos.

Em suma, a análise em sua natureza semiótica, objetivou também fazer uma reflexão de como a compreensão do conceito de vivência pode dar contribuições para as habilidades de pensamento crítico aos estudantes em geral.

Em Goethe, Nietzsche e Foucault, existe uma noção comum de conceber Educação e Filosofia, e é o conceito de vivência que melhor explicita o que há em comum entre os pensamentos dos três.

Antes de analisar a relação dos autores com o conceito de vivência, faz-se necessário a análise da gênese e significados da palavra, a qual segundo Viesenteineir (2013) tem a sua ocorrência como Erlebnis e

aparece no vocabulário alemão pela primeira vez a partir da metade do século XIX, e ganha estatuto filosófico só em meados do mesmo século. Substantivado a partir do verbo erbelen, Erlebnis significa "estar ainda presente na vida quando algo acontece", e seu uso lingüístico geral remonta à literatura de caráter biográfico que surge inicialmente com o texto de Dilthey sobre a vida de Schleiermacher (VIESENTEINEIR, 2013, p. 142)

Viesenteiner (2013) também nos esclarece os três aspectos principais do uso geral da palavra Erlebnis: 1) vivência com o caráter de ligação imediata com a vida. 2) o que é vivenciado deve ter uma intensidade de tal modo significativa, cujo resultado confere uma importância que transforma por completo o contexto geral da existência. 3) seu emprego deve ser pensado do ponto de vista estético, pois há a impossibilidade de determinar racionalmente o conteúdo da vivência, ou seja, não é possível exprimir pela linguagem a abundância de sentimento dessa Erlebnis, não existem meios racionais que expliquem tal conteúdo.

Imediatez, significabilidade e incomensurabilidade são, então, tentativas de exprimir por palavras o conceito de vivência, tarefa nada fácil, pois segundo Foucault há, entre a linguagem e o sujeito, uma relação intrínseca, indissociável e na linguagem se perde muito do que se quer descrever e se ganha muito de quem está descrevendo:

Mas pode ser também que esteja para sempre excluído o direito de pensar ao mesmo tempo o ser da linguagem e o ser do homem; pode ser que haja aí como que uma indelével abertura de tal forma que seria preciso rejeitar como quimera toda a antropologia que pretendesse tratar do ser da lingua- 
gem, toda concepção da linguagem ou da significação que quisesse alcançar, manifestar e liberar o ser próprio do homem (FOUCAULT, 2007, p.468)

Há também o caráter estritamente individual de toda vivência, pois a vivência é sempre única para cada ser, com significados próprios para cada um.

A vivência em si somente pode ser traduzida depois de vivida, sendo assim, só pode ser explicado o sentido que damos a vivência, além disso, temos que:

O significado originário de Erlebnis implica em um estreito vínculo com a noção de pathos, ou seja, como uma espécie de "conquista" de um excesso perdulário de vida que não é oriundo da sistematização teórica sobre uma certa forma de vida, mas se origina do solo mesmo da travessia existencial de uma vivência. Pathos e erlebnis não são oposições, mas uma vivência é propriamente pathos, o padecimento da travessia através de uma vivência. (VIESENTEINEIR, 2013, p.146)

Erlebnis e pathos estão estreitamente vinculados, só temos reflexões, avaliações e julgamentos das vivências, produtos tardios da natureza, então não somos, desta forma, contemporâneos de nós mesmos, fato este paradoxal e intrigante, que nos intriga muito e também intrigou a Nietzsche, a ponto de achá-la misteriosa.

\section{BREVES CONSIDERAÇÕES SOBRE O CONCEITO DE VIVÊNCIA EM NIETZSCHE E GOETHE}

Vivência então é o tempo presente, diferente de passado e de futuro, com a vivência nos vinculamos ao presente, ela é tudo o que temos, ela é tudo o que existe de fato e para Nietzsche é trágico o fato de que no fundo de tudo existe a vivência, que não é algo objetivo, há somente reflexões da vivência e por existir essa defasagem, reside aí uma tragédia.

Para Viesenteiner (2013)

Seja a imediatez homem-mundo, a significabilidade para o contexto geral da vida e ainda a impossibilidade de comensurar racionalmente o conteúdo da vivência, ou seja, sua dimensão estética, todas elas encontram ecos nos textos de Nietzsche. (VIESENTEINER, 2013, P. 154)

Para Nietzsche também Erlebnis significa pathos e ao longo de seus escritos, o conceito recebe outras variações semânticas, como autogenealogia em "Crítica da razão da vida".

Cada vivência é única e talvez aí repouse a verdade de que o "extraordinário" está justamente no "ordinário", assim como os gregos acreditavam e adotavam como modo de vida. O modo próprio de ser grego é o da valorização das coisas ao redor, herói é quem luta ao meu lado, Deus é tudo, é ar, é água, há o significado de vivência do instante como a única coisa preciosa que existe na vida.

Em “A Gaia Ciência”, aforismo 354, Nietzsche clarifica que a consciência é um estágio inferior, é secundária, linguagem, pensamento e consciência estão abaixo da vivência; podemos ter linguagem sem consciência, pensamento não é o auge, tudo pode ser feito sem consciência, pois

Todas as nossas ações, no fundo, são pessoais de maneira incomparável, únicas, ilimitadamente individuais, não há dúvida; mas, tão logo as traduzimos para a consciência, não parece mais sê-lo. Este é o verdadeiro fenomenalismo e perspectivismo, como eu o entendo: a natureza da 
consciência animal ocasiona que o mundo de que podemos nos tornar conscientes seja só um mundo generalizado, vulgarizado - que tudo o que se torna consciente está relacionada uma grande, radical corrupção, falsificação, superficialização e generalização (NIETZSCHE, 2001, p. 250)

Juntamente com Goethe, Nietzsche e Foucault temos Pierre Hadot, concordando com o fato de que os gregos foram os únicos que ensinaram que não há separação entre pensar e viver, para os gregos a única razão de ser a filosofia seria viver coerentemente com o modo de pensar, inclusive Hadot nos recomenda: "Lembra de Viver".

No desejo de fundamentação que a Filosofia tem, encontramos Fausto de Goethe, e o dilema de Fausto é também o dilema de Nietzsche. Fausto representa aquela pessoa que fica se perguntando e não encontra respostas, que ao buscar o indefinido, o infinito e a perfeição e que ao tentar ampliar o próprio ser; encontra "coisas" e não respostas objetivas. O dilema de Fausto também era: como viver sem enlouquecer? Com compulsão pelo conhecimento; como conciliar compulsão com a impossibilidade de alcançar a verdade?

Fausto se apresenta como uma grande obra literária, escrita em 57 anos por Goethe, possui vários significados, signos infinitos. Fausto nos revela "coisas" que todas as pessoas em seus quartos de trabalho já devem ter pensado. Ele quer ampliar o próprio ser, deseja estar em todo lugar e em nenhum lugar ao mesmo tempo, só quer o que não é terrestre, tem fermento que cresce ao infinito. Fausto é o moderno. Goethe faz um acerto de contas consigo mesmo por meio dessa obra.

A vivência para Goethe é um ponto certo para valorização da vida, a valorização da vivência em Goethe e em Nietzsche, significa valorizar e viver cada instante, cada momento, de certa forma Fausto nos ensina isso também.

Os gregos representam o que significa viver no presente, a leitura de Winckelmann de Goethe nos diz isso. Também em Winckelmann temos que: o único, o inesperado, só ocorre quando tudo se reúne em si mesmo em igual medida e desenvolve todas as capacidades, a formação integral (também isso os gregos nos ensinam) reúne em si todas (boas e ruins) capacidades e desenvolve-as.

Goethe também faz crítica ao eruditismo com fim em si mesmo; livro é apenas complemento da vivência, quer aprender sobre os homens? Esteja entre homens, VIVA. Surgem então questões: Como educar homens? Como formá-los? Qual é o papel das vivências em sua formação?

\section{FORMAÇÃO - INCORPORAÇÃO DAS VIVÊNCIAS}

A formação é a incorporação das vivências, no domínio da Liberdade, quando se quer formar, se quer mudar,

Ora, na medida em que o "destino da tarefa" de se tornar o que é, como reza a fórmula, pressupõe que "não se suspeite sequer remotamente o que é", não resta nenhuma outra possibilidade de formação a não ser através de um exercício ou cultivo do homem sobre si mesmo que, neste caso, se dá através das vivências. (VIESENTEINER, 2009, p.209)

Outro modo de conceber a formação implica novo modo de conceber o humano, o que não se converter em vivência, é inútil.

Para Nietzsche a formação além de se dar pelas vivências também se dá a partir de mudanças de hie- 
rarquias da composição do próprio ser, do que ele é composto, do que ele é feito.

Pensar o ser como um composto, múltiplo. Nietzsche nos diz que você é o que é porque sua organização, de valores morais, valores políticos, sua alimentação, sua religião etc, se constitui de tal modo e não de outro, ou seja, a organização de suas forças, de tudo isso e muito mais. O que pode mudar são as hierarquias das constituições dos seres humanos.

Nietzsche acreditava no Educar para ser simples no pensamento, que para nós modernos, que não nascemos simples, somos complexos, nos restam exercícios, busca e formação para a simplicidade.

Simples para os gregos implica em reconhecer que o mundo não é composto de fundamentos morais e sim de cosmos, de composições, constituídos de elementos coesos, explicações diretas das coisas, com a linguagem simplificando o que é complexo, falseando de certa forma o que o mundo é, mas nos ajudando na sobrevivência.

É no mundo que a formação se dá e Wilhelm Meister de Goethe, no diz isso, ele sai do seu quarto e vive...

\section{MINHA VIVÊNCIA DO FILME “DIAS DE NIETZSCHE EM TURIM”}

Quem sai do quarto e vive e entra no quarto e escreve o que viveu é Nietzsche e o que segue nas próximas linhas é a vivência do filme por uma educadora, a ideia da análise do filme surgiu com o objetivo de elucidar algumas vivências de Nietzsche em Turim:

De longe se ouve o sino, Nietzsche anda pelas ruas de Turim, repara nas grandes janelas, lê placas e anda atento a tudo em sua volta. Chega a seu quarto de trabalho e começa a escrever cartas, fala sobre a brisa, que dá asas aos seus pensamentos mais pesados, as calçadas de Turim são paraísos para seus pés, só os pensamentos que temos caminhando, valem alguma coisa. Eis a cidade de que precisava, cidade digna, severa, onde há uma ponte além do bem e do mal.

Ainda em seu quarto... enfim livrou-se de Wagner, superação de si, filósofos não amam palavras bonitas, se desligou de Wagner quando ele se virou para um Deus alemão, Nietzsche não é músico para não ser romântico, porém sem a música a vida seria um erro.

Há um diálogo agora no filme, entre Nietzsche e algumas pessoas, porém não se ouve o conteúdo da conversa, apenas percebem-se os gestos, as expressões, ouvimos os trovões lá fora e o tic tac do relógio, quando uma mulher toca piano lindamente, causando impressões e sensações indescritíveis nele (Nietzsche) e em nós que assistimos o filme.

Ao som do piano ele sobe as escadas e reflete que não perdeu um só dia de trabalho desde que chegou a Turim e que tem um sobretudo de outono muito elegante. Os dias são de uma luminosidade e ele viu o outono, uvas e outras frutas melhores, a cidade calma com seus trezentos mil habitantes. Observa estátuas, monumentos da cidade, o sino toca mais uma vez, os cavalos passam pelas ruas, levando as carruagens...

Tornamos a nós mesmos obras primas, assiste óperas e ouve obras primas...e agora em sua mesa de trabalho, escreve que alguns homens nascem póstumos.

No alfaiate, enquanto tira suas medidas ele pensa: o corpo é o pensador e que fazia dez anos que não trazia ao corpo uma roupa que lhe agradasse. O sino toca mais uma vez e ele está novamente em seu quarto de trabalho, escrevendo cartas aos resenhistas de suas obras, à Fritz, condenando-o pelo uso do nome de 
Zaratustra em vão...

Recita o aforismo 341 de A Gaia Ciência

Esta vida, como você a está vivendo e já viveu, você terá de viver mais uma vez e por incontáveis vezes; e nada haverá de novo nela, mas cada dor e cada prazer e cada suspiro e pensamento, e tudo o que é inefavelmente grande e pequeno em sua vida, terão de lhe suceder novamente, tudo na mesma sequência e ordem - e assim também essa aranha e esse luar entre as árvores, e também esse instante e eu mesmo. A perene ampulheta do existir será sempre virada novamente - e você com ela, partícula de poeira!. Você não se prostraria e rangeria os dentes e amaldiçoaria o demônio que assim falou? Ou você já experimentou um instante imenso, no qual the responderia: "Você é um deus e jamais ouvi coisa tão divina". (NIETZSCHE, 2001, p.230)

E a resposta dele é Não (e a minha também) e assim se encerra seu quadragésimo quarto ano de vida ao som de violinos, ele está admirando a arquitetura de Turim e sabe sua sina de que será lembrado um dia, como uma dinamite, alguém que teve a fortuna da existência na fatalidade, no enigma, alguém que estava morto como seu pai e ainda vive e envelhece como sua mãe.

Alguém que no dionísico encontrou no interior do homem algo de sobrenatural, o homem que se torna uma obra de arte. Relacionou o bem e o mal para que um dependa do outro. Em meio à natureza, reflete que teve que voar às alturas para ter a nascente do prazer, da longa experiência da andança no gelo e no deserto, para surgir à pergunta: Quanto de verdade o homem suporta? E na filosofia experimental, tem a vontade do não, mas encontra a fórmula do amor fati.

No barbeiro de Sevilha ele encontra o revirar das perspectivas e em meio a trovões e diz sobre sua arte: comunicar pathos por meio de filos, pois há nele (e em nós), muitas possibilidades de estilos, no difícil encontro consigo mesmo.

Valsa com ele mesmo na incerteza de seus dias, dentro de seu quarto, e em suas cartas a Richard Wagner e a Ariana, diz que ele ser um homem é uma desvantagem, mas viveu entre homens e conhece tudo o que um homem pode provar, das mais altas as mais baixas, diz que não terá muito tempo.

Em meio à sua loucura, ele recebe um rei imaginário em seu quarto, e dança nu com uma máscara, a máscara de Dionísio, fora de si, a libertação efetiva, como ato de afirmação da vida.

Vê que é preciso fazer sacrifícios.... "agradeço o céu pelo mundo antigo, criminoso honesto, cada nome da história sou eu... vejo-me nu em meu próprio funeral.... bato nas costas dos outros e digo: Você está contente? Sou Deus!!....com cordial afeto....Seu Nietzsche"

"Seja como fores, sejas tua própria fonte de experiências, jogues fora o descontentamento, perdoa a ti mesmo, está tudo em teu poder... misturado com tuas vivências... " assim falou Nietzsche...

\section{CONSIDERAÇÕES FINAIS}

A grande virtude do filme reside na sensibilidade para compreender o homem e o momento, ou seja, a vivência (erlebnis) de um homem, a nostalgia do filósofo, suas angústias, frustrações e decepção amorosa, os conflitos da existência que o levaram a reflexões filosóficas. E todas essas reflexões filosóficas devem funcionar como um trampolim para a atividade humana prática, para o melhoramento efetivo das condições 
impostas pela vida, devem impulsionar uma reflexão do homem em sua dimensão mais "humana" que há, E o olhar que podemos dar aos nossos alunos diante desse entendimento, dessa profundidade que é o ser humano, como podemos como educadores entendê-los e ajudá-los em sua formação diante do fato de saber que a formação é incorporação de vivências, temos que proporcionar vivências mais diversas e efetivas nas disciplinas que lecionamos.

As vivências (erlebnis) de Nietzsche em Turim, suas frustrações, desejos, sensações, distrações, suas confissões mais secretas a si mesmo, suas reflexões sobre a sua vida e análise do comportamento dos demais em uma postura filosófica existencialista sobre o bem e o mal, representaram a fertilidade e o paradoxo de sua evolução espiritual, um pouco antes de enlouquecer e ficar calado por anos entre abril de 1888 e janeiro de 1889, foi o palco onde o filósofo escreveu Ecce Homo e Anticristo.

Vemos no filme um homem que refletiu o que viveu, e viveu o que refletiu, o filme nos traz a sua escrita aforismática, composta por trechos objetivos, ambíguos ou simplesmente "sugestivos", e por meio dela, vemos refletido o momento intelectual do filósofo.

As imagens do filme são costuradas como se estivessem funcionando dentro da mente do filósofo. Excertos d'O Caso Wagner e do Ecce Homo (1888), articulados com trechos aparentemente reescritos a partir do Além do bem e do mal, dão o grau de acuidade com que Nietzsche parecia olhar a vida.

Diante então do conceito de vivência (erlebnis) temos a interpretação de seu "signo Nietzsche" e o que ele tem de mais vivo, vivificando suas volições e sensações, suas vivências serviram e servem para reflexões das nossas próprias vivências, pessoais e profissionais.

\section{REFERÊNCIAS}

FOUCAULT, Michel. As Palavras e as coisas: uma arqueologia das ciências humanas. São Paulo: Martins Fontes GOETHE, J. W. Fausto. São Paulo: Martin Clarit, 2006

GOETHE, Johann W. "Winckelmann", in Laocoonte e altri scritti sull'arte (1789-1805). A cura di Roberto Venuti. Roma: Salerno Editrice, 1994.

GOETHE (1749-1832). Wilhelm Meister's Apprenticeship. The Harvard Classics Shelf of Fiction. 1917.

VIESENTEINER, Jorge Luiz. O conceito de Vivência (Erlebnis) em Nietzsche: Gênese, significado e Recepção. Kriterion, nำ127: Belo Horizonte, 2013.

VIESENTEINER, Jorge Luiz. Experimento e vivência: a dimensão da vida como pathos - Tese de Doutorado. UNICAMP, 2009

NIETZSCHE, F. W. A Gaia Ciência. São Paulo: Companhia das letras, 2001.

Filme "Dias de Nietzsche em Turim" - https://www.youtube.com/watch?v=w3ylsyq7zzg 